\title{
Brown Marmorated Stink Bug (Hemiptera: Pentatomidae) Infestations in Tree Borders and Subsequent Patterns of Abundance in Soybean Fields
}

\author{
B. L. Aigner, ${ }^{1}$ T. P. Kuhar, D. A. Herbert, C. C. Brewster, J. W. Hogue, and J. D. Aigner \\ Department of Entomology, Virginia Polytechnic Institute and State University, Blacksburg, VA 24061-0319 (baigner@vt.edu; tkuhar@ \\ vt.edu; herbert@vt.edu; carlyleb@vt.edu; hogue@vt.edu; daigner@vt.edu), and 'Corresponding author, e-mail: baigner@vt.edu
}

Subject Editor: Michael Brewer

Received 19 October 2016; Editorial decision 17 January 2017

\begin{abstract}
The invasive brown marmorated stink bug, Halyomorpha halys (Stål) (Hemiptera: Pentatomidae), is an important pest of soybean (Glycine max L. Merr.) in the Mid-Atlantic United States. In order to assess the influence of nonmanaged wooded borders on $H$. halys infestation patterns in soybean, 12 soybean fields in Orange and Madison Counties, VA, were sampled each week from July to October in 2013 or 2014 for H. halys. At each location, five 2-min visual counts of $H$. halys life stages were made on tree of heaven (Ailanthus altissima Mill.) and other favorable host trees along a wooded border, on the adjacent soybean edge, $15 \mathrm{~m}$ into the soybean field, and $30 \mathrm{~m}$ into the field. Seasonal data showed a clear trend at all locations of $H$. halys densities building up on A. altissima-dominated wooded borders in July, then, gradually moving into adjacent soybean field edges later in the summer. Halyomorpha halys did not move far from the invading field edge, with approximately half as many bugs being present at $15 \mathrm{~m}$ into the field and very few being detected $30 \mathrm{~m}$ into the field. These results have implications for continued monitoring and management using field border sprays, particularly on edges adjacent to woods.
\end{abstract}

Key words: Halyomorpha halys, Ailanthus altissima, soybean, field edge

Since its invasion into the United States in the late 1990s, the brown marmorated stink bug, Halyomorpha halys (Stål) (Hemiptera: Pentatomidae), has established itself as a conspicuous household nuisance and important agricultural pest throughout the MidAtlantic United States. (Rice et al. 2014). Soybean (Glycine max L. Merr.) is among the many crops attacked by this polyphagous pentatomid (Nielsen and Hamilton 2009, Nielsen et al. 2011). Feeding during pod development stages results in aborted pods and underdeveloped flat pods. In later stages of seed development, this generally causes shriveled, deformed, and aborted seeds (Owens et al. 2013). Stink bug feeding in soybean also can cause "stay-green" or "green stem" syndrome where the plant delays maturation in an effort to compensate for seed that may have been aborted due to feeding (Hill et al. 2006, Rice et al. 2014). Complete yield loss can result from mechanical issues that ensue from attempting to harvest soybeans that have not fully senesced (Cissel et al. 2015). A better understanding of the landscape and ecological factors influencing $H$. halys populations aids in the development of effective management strategies (Wallner et al. 2014). Venugopal et al. (2014) analyzed the effect of adjacent habitat on $H$. halys infestations in soybeans in
Maryland and reported that fields adjacent to wooded, crop, and building habitats harbored higher densities of stink bugs than those adjacent to open habitats. Stay green syndrome also appears to be largely associated with field borders. Additional studies have shown that nonmanaged forested areas, in particular, are thought to be important season-long reservoirs for dispersal of $H$. halys to agricultural crops (Bakken et al. 2015). In Virginia, we have observed particularly high densities of $H$. halys on the invasive tree of heaven, Ailanthus altissima Mill., which has become the most dominant tree species along the edges of forests and roadways in Virginia (McAvoy et al. 2012). Moreover, based on annual surveys of soybeans across Virginia from 2011 to 2012, the soybean fields having highest $H$. halys pest pressure were typically bordered by woods containing A. altissima. Thus, in order to better understand the relationship between $H$. halys and A. altissima-dominated wooded borders, the seasonal abundance of $H$. halys life stages was sampled on this tree species adjacent to soybean fields, and at different distances into the soybean field. A better understanding of $H$. halys infestation patterns in fields should aid in the development of improved pest management strategies for soybeans and other crops. 


\section{Materials and Methods}

Five soybean fields in Orange County and three fields in Madison County were sampled once a week from early July to October in 2013 (Table 1). In 2014, four fields in Madison County were sampled in the same months. All fields that were chosen had at least one border of woods with A. altissima and other favorable host trees such as mulberry (Morus nigra L.) and Princess Tree (Paulownia tomentosa Thunb. Steud.; Bakken et al. 2015). At each field, five 2 min visual samples, roughly $80 \mathrm{~m}$ apart, were taken in four separate sample zones. These zones are known in this experiment as the wooded border (containing A. altissima and alternate host trees), the adjacent soybean field edge ( $<1 \mathrm{~m}$ into the field), at $15 \mathrm{~m}$ into the soybean field, and at $30 \mathrm{~m}$ into the soybean field. All $\mathrm{H}$. halys adults, nymphs, and eggs were recorded. Given the difference in habitat or microhabitat structures and characteristics between the soybean fields and the wooded borders, technicians thoroughly scanned and focused on and around plant parts that are most attractive to stink bugs (seed pods). Additionally, tree surveys were conducted along the wooded borders of sampled fields to document species composition. All mature tree species were recorded within a 15.24-m linear transect at four separate sections of each field.

\section{Statistical Analysis}

The 2013 and 2014 stink bug data were analyzed separately to examine differences in counts with respect to sampling zone in and around soybean fields and sampling date. Because the data were counts of nymphs and adults collected over time at the same fields, a repeated measures generalized linear mixed model with a Poisson distribution and first-order autoregressive covariance structure (Darbro and Harrington 2006, Stroup 2012) was used for analysis. For each analysis, sample zone and sampling date, and their interactions were the fixed effects factors, field was the random effects factor, and sampling date and sample zone in field were the repeated measures parameter and subject, respectively. Degrees of freedom were calculated using the Satterthwaite approximation method (West et al. 2006), and post hoc tests were carried out using Fisher's protected LSD. Statistical analyses were performed using SPSS 24 (IBM Corp. 2016) at a significance level of $\alpha=0.05$.

\section{Results and Discussion}

Populations of $H$. halys were found at all 12 field locations, and wooded borders were composed of an average of $56 \%$ A. altissima (followed by $21 \%$ Juniperus virginiana, $8 \%$ Carya ovata, $~ 1 \%$
Quercus alba, Quercus rubra, etc.). In 2013, significant differences in the densities of nymphs $(F=46.939 ; \mathrm{df}=3,159 ; P<0.0001)$ and adults $(F=29.648 ; \mathrm{df}=3,120 ; P<0.0001)$ were found among the four sample zones, with the highest occurrences of both life stages at the field edges followed by the wooded borders (Fig. 1A and B). Although there were also significant differences among the sample zones with respect to nymphs $(F=20.293 ; \mathrm{df}=3,40 ; P<0.0001)$ and adults $(F=62.017 ; \mathrm{df}=3,58 ; P<0.0001)$ in 2014, the highest occurrences were in the wooded borders rather than the field edges (Fig. 2A and B).

In 2013, the densities of $H$. halys nymphs $(F=18.273$; $\mathrm{df}=27$, 191; $P<0.0001)$ and adults $(F=6.406 ; \mathrm{df}=29,146 ; P<0.0001)$ differed significantly over the sampling dates with respect to the sample zones. Similarly, in 2014, both nymph $(F=2.277$; $\mathrm{df}=26$, $104 ; P<0.0001)$ and adult $(F=10.154 ; \mathrm{df}=27,58 ; P<0.0001)$ densities varied significantly among the sample zone over time. In general, the densities of $H$. halys nymphs increased on A. altissima and other host trees in the wooded borders in July 2013 (Fig. 1C and D) and 2014 (Fig. 2C and D). By August, H. halys nymphs and adults began appearing on the adjacent soybean borders in many of the fields, with densities peaking on the crop during the R5 and R6, beginning and full seed development growth stages (Fehr and Caviness 1977) in late August. Venugopal et al. (2015a) also found the highest densities of $H$. halys on R5 to R6 stage soybeans.

There was a significant effect of sampling zone on density of $H$. halys with respect to date in both years, with most bugs not moving far from the invading field edge; approximately half as many bugs being present at $15 \mathrm{~m}$ into the field and very few being detected in the field at $30 \mathrm{~m}$ in 2013 (Fig. 1C and D) and 2014 (Fig. 2C and D). These results are very similar to those of Venugopal et al. (2015a) for soybeans and corn sampled in Maryland, and follow a general pattern for $H$. halys being a border-inhabiting agricultural pest in tree crops as well (Blaauw et al. 2014, Joseph et al. 2014, Venugopal et al. 2015b).

Our study confirms that $H$. halys populations are in relatively high numbers on A. altissima and other mixed hardwood trees during the early summer (Bakken et al. 2015) when soybean is in vegetative stages of growth. As the crop matures into pod and seed development stages, $H$. halys densities gradually increase at the field edge and have a high tendency to remain on field edges throughout the season. As pod and seed development begins to occur, H. halys move into the edge in order to feed until the plant is no longer a desirable food source. Treating only field edges has been introduced and exploited as an IPM strategy that was very quickly adopted by growers and agricultural consultants. This study contributed to a

Table 1. Field sampling locations and date of first sample at 12 soybean fields in Orange or Madison County, VA

\begin{tabular}{|c|c|c|c|}
\hline First sample date (soybean growth stage) & Location & GPS Coordinates & \\
\hline 9 July 2013 (R1) & Orange 1 & 38.2355 & -78.1097 \\
\hline 9 July 2013 (V6) & Orange 2 & 38.2125 & -78.2419 \\
\hline 9 July 2013 (V6) & Orange 3 & 38.1727 & -78.248 \\
\hline 9 July 2013 (V6) & Orange 4 & 38.1722 & -78.2444 \\
\hline 9 July 2013 (V7) & Orange 5 & 38.1755 & -78.243 \\
\hline 25 July 2013 (R2) & Madison 1 & 38.2883 & -78.1411 \\
\hline 25 July 2013 (R2) & Madison 2 & 38.3005 & -78.1411 \\
\hline 25 July 2013 (R2) & Madison 3 & 38.3297 & -78.13 \\
\hline 18 July 2014 (R2) & Madison 1 & 38.2998 & -78.1450 \\
\hline 18 July 2014 (R2) & Madison 2 & 38.3030 & -78.1489 \\
\hline 18 July 2014 (R2) & Madison 3 & 38.3069 & -78.1357 \\
\hline 18 July 2014 (R2) & Madison 4 & 38.3356 & -78.1274 \\
\hline
\end{tabular}




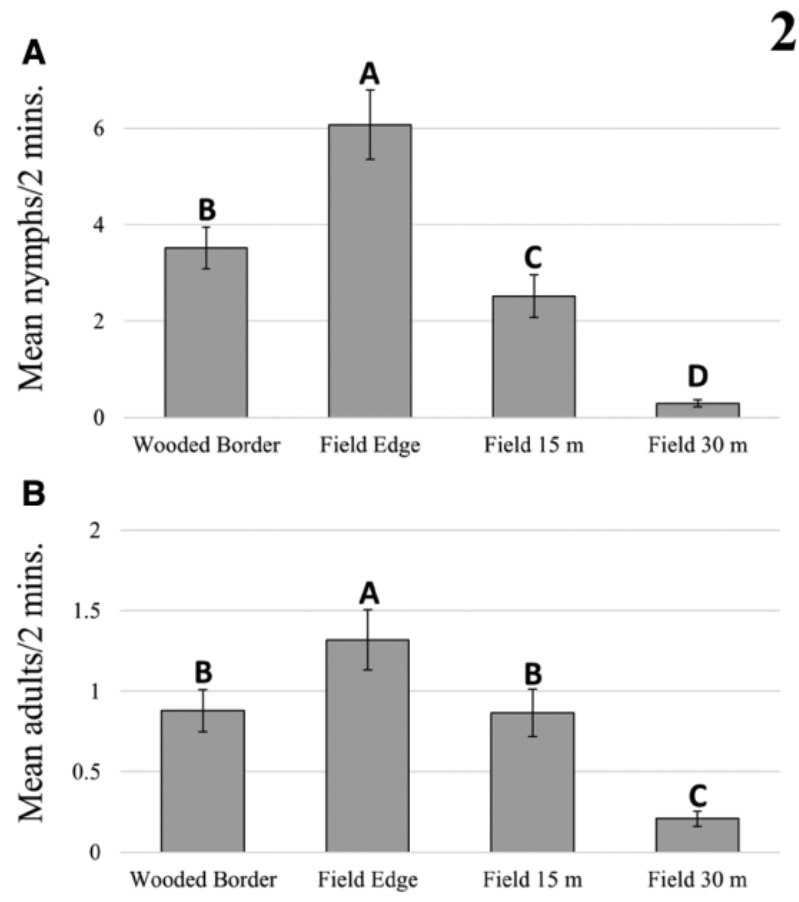

Sample Zone
2013

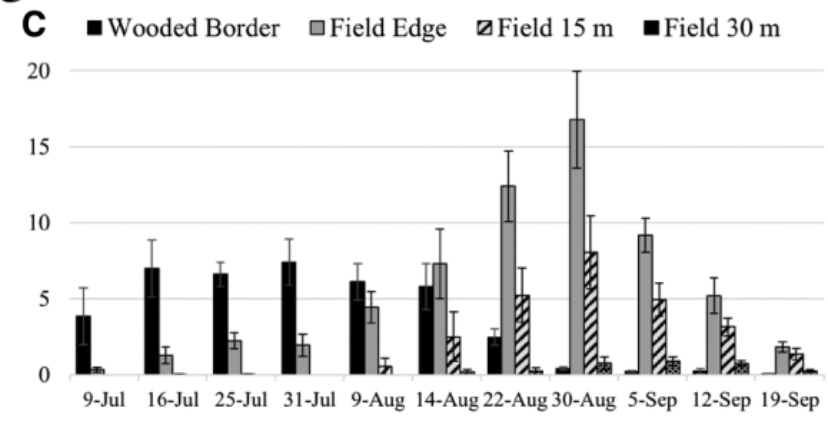

D

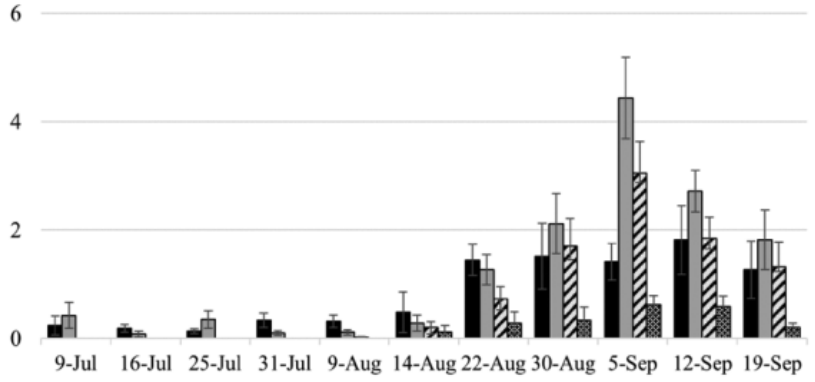

Sample Date

Fig. 1. Cumulative and seasonal mean \pm SEM number of $H$. halys nymphs ( $\mathbf{A}$ and $\mathbf{C}$, respectively) and adults (B and $\mathbf{D}$, respectively) observed in different zones around or in soybeans in central Virginia in 2013. Bars of different zones characterized by the same letter are not significantly different (Fisher's protected LSD, $P \leq 0.05)$.

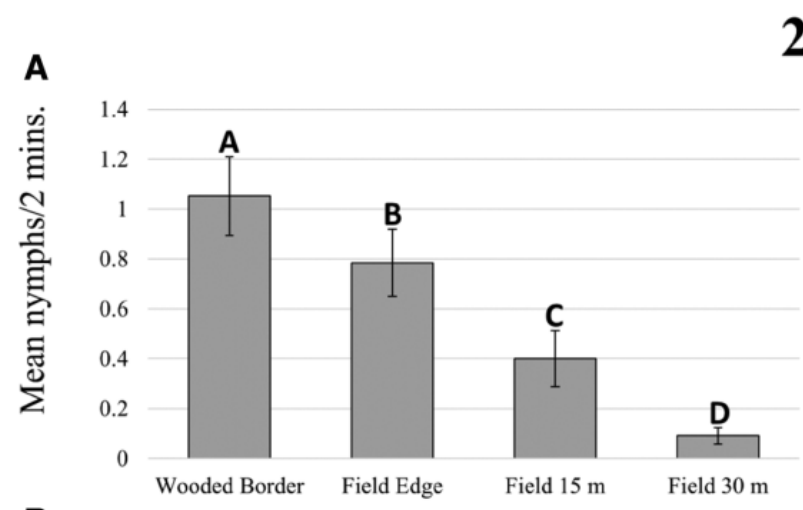

B

$2014_{c}$

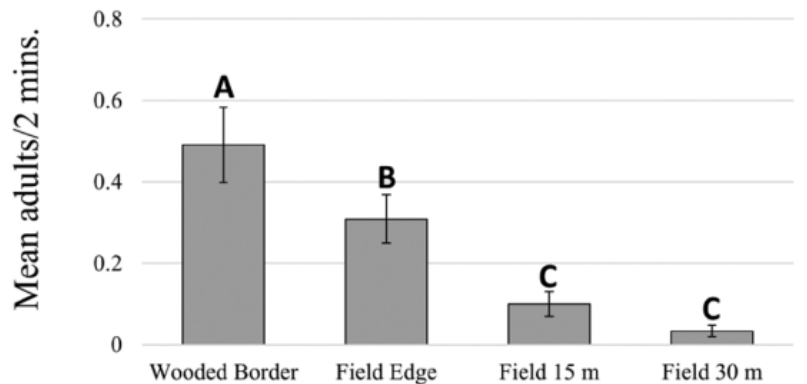

Sample Zone

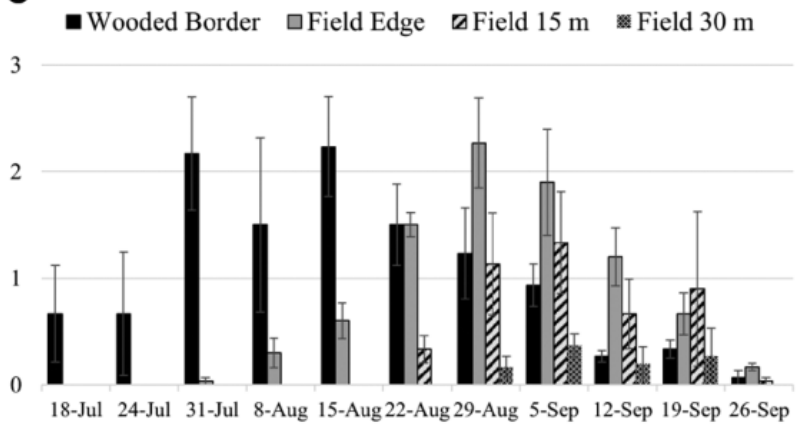

D

3

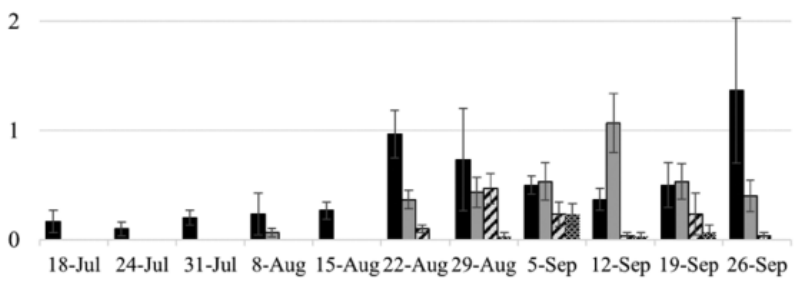

Sample Date

Fig. 2. Cumulative and seasonal mean \pm SEM number of $H$. halys nymphs ( $\mathbf{A}$ and $\mathbf{C}$, respectively) and adults (B and $\mathbf{D}$, respectively) observed in different zones around or in soybeans in central Virginia in 2014. Bars of different zones characterized by the same letter are not significantly different (Fisher's protected LSD, $P \leq 0.05)$. 
multistate project on the biology and management of $H$. halys in Mid-Atlantic U.S. soybeans, the results and implications of which have been published in a bulletin (see Cissel et al. 2015).

\section{Acknowledgments}

Funding provided in part by the Virginia Agricultural Council and the Virginia Soybean Board.

\section{References Cited}

Bakken, A. J., S. C. Schoof, M. Bickerton, K. L. Kamminga, J. C. Jenrette, S. Malone, M. A. Abney, D. A. Herbert, Jr., D.T.P. Kuhar, and J. Walgenbach. 2015. Occurrence of brown marmorated stink bug (Hemiptera: Pentatomidae) on wild hosts in nonmanaged woodlands and soybean fields in North Carolina and Virginia. Environ. Entomol. 44: 1011-1021.

Blaauw, B. R., D. Polk, and A. L. Nielsen. 2014. IPM-CPR for peaches: Incorporating behaviorally-based methods to manage Halyomorpha halys and key pests in peach. Pest Manage. Sci. 71:1513-1522.

Cissel, B., J. Whalen, G. Dively, C. Hooks, T. Patton, P. D. Venugopal, B. Aigner, J. Hogue, A. Herbert, T. Kuhar, et al. 2015. Brown marmorated stink bug biology and management in Mid-Atlantic soybeans. Virginia Cooperative Extension. ENTO - 168NP.

Darbro, J. M., and L. C. Harrington. 2006. Bird-baited traps for surveillance of West Nile mosquito vectors: effect of bird species, trap height, and mosquito escape rates. J. Med. Entomol. 43: 83-92.

Fehr, W. R., and C. E. Caviness. 1977. Stages of soybean development. Cooperative Extension Service, Agriculture and Home Economics Experiment Station, Iowa State University, Ames, Iowa.

Hill, C. B., G. L. Hartman, R. Esgar, and H. A. Hobbs.2006. Field evaluation of Green Stem Disorder in soybean cultivars. Crop Sci. 46: 879-885.

IBM Corp 2016. IBM SPSS for Windows, Version 24.0.0. Armonk, NY.

Joseph, S. V., J. W. Stallings, T. C. Leskey, G. Krawczyk, D. Polk, B. Butler, and J. C. Bergh. 2014. Spatial distribution of brown marmorated stink bug (Hemiptera: Pentatomidae) injury at harvest in Mid-Atlantic apple orchards. J. Econ. Entomol. 107: 1839-1848.
McAvoy, T., A. L. Snyder, N. Johnson, S. M. Salom, and L. T. Kok. 2012. Road survey of the invasive Tree-of-Heaven (Ailanthus altissima) in Virginia. Invasive Plant Sci. Manage. 506-512. (Oct-Dec 2012):

Nielsen, A. L., and G. C. Hamilton. 2009. Seasonal occurrence and impact of Halyomorpha halys (Hemiptera: Pentatomidae) in tree fruit. J. Econ. Entomol. 102: 1133-1140.

Nielsen, A. L., G. C. Hamilton, and P. W. Shearer. 2011. Seasonal phenology and monitoring of the non-native Halyomorpha halys in soybean. Environ. Entomol. 40: 231-238.

Owens, D., D. A. Herbert, G. Dively, D. Reisig, and T. Kuhar. 2013. Does feeding by Halyomorpha halys (Hemiptera: Pentatomidae) reduce soybean seed quality and yield? J. Econ. Entomol. 106: 1317-1323.

Rice, K. B., C. J. Bergh, E. J. Bergmann, D. J. Biddinger, C. Dieckhoff, G. Dively, H. Fraser, T. Gariepy, G. Hamilton, T. Haye, et al. 2014. Biology, ecology, and management of brown marmorated stink bug (Hemiptera: Pentatomidae). J. Integr. Pest Manag. 5: A1-A13.

Stroup, W. W. 2012. Generalized Linear Mixed Models: Modern Concepts, Methods and Applications. CRC Press, New York, NY.

Venugopal, P. D., P. L. Coffey, G. P. Dively, and W. O. Lamp. 2014 Adjacent habitat influence on stink bug (Hemiptera: Pentatomidae) densities and the associated damage at field corn and soybean edges. PLoS ONE 9: e109917.

Venugopal, P. D., G. P. Dively, and W. O. Lamp. 2015a. Spatiotemporal dynamics of the invasive Halyomorpha halys (Hemiptera: Pentatomidae) in and between adjacent corn and soybean fields. J. Econ. Entomol. 108: 2231-2241. doi: 10.1093/jee/tov188.

Venugopal, P. D., H. M. Martinson, E. J. Bergmann, P. M. Shrewsbury, and M. J. Raupp. 2015b. Edge effects influence the abundance of the invasive Halyomorpha halys (Hemiptera: Pentatomidae) in woody plant nurseries. Environ. Entomol. 44: 474-479. doi: 10.1093/ee/nvv061.

Wallner, A. M., G. C. Hamilton, A. L. Nielsen, N. Hahn, E. J. Green, and C. R. Rodriguez-Saona. 2014. Landscape factors facilitating the invasive dynamics and distribution of the brown marmorated stink bug, Halyomorpha halys (Hemiptera: Pentatomidae), after arrival in the United States. PLoS ONE 9: e95691. doi: 10.1371/journal.pone.0095691

West, B., K. Welch, and A. Galecki. 2006. Linear mixed models: A practical guide using statistical software. CRC Press, New York, NY. 